\title{
Recommended minimal standards for description of new staphylococcal species
}

\author{
J. Freney, ${ }^{1}$ W. E. Kloos, ${ }^{2}$ V. Hajek ${ }^{3}$ and J. A. Webster ${ }^{4}$, for the \\ Subcommittee on the taxonomy of staphylococci and streptococci of \\ the International Committee on Systematic Bacteriology, with the help \\ of M. Bes, ${ }^{1}$ Y. Brun ${ }^{1}$ and C. Vernozy-Rozand ${ }^{5}$
}

Author for correspondence: J. Freney. e-mail: hehbac@laennec.univ-lyon1.fr

\footnotetext{
1 Centre National de Référence des Staphylocoques, Faculté de Médecine RTH Laënnec, F-69008 Lyon, France

2 College of Agriculture and Life Sciences, Raleigh, NC 27695-7614, USA

3 Institute of Medical Microbiology, Palacky University, 77515 Olomouc, Czech Republic

4 Qualicon Inc., a DuPont subsidiary, Wilmington, DE 19880-0402, USA

5 Unité de Microbiologie Alimentaire et Prévisionnelle, Ecole Nationale Vétérinaire de Lyon, F-69280 Marcy I'Etoile BP83, France
}

\begin{abstract}
In accordance with Recommendation $30 \mathrm{~b}$ of the International Code of Nomenclature of Bacteria, minimal standards are proposed for the genus Staphylococcus and the description of newly recognized species in this genus. Assignment of a strain to the genus Staphylococcus requires that it is a Grampositive coccus that forms clusters, produces catalase, has an appropriate cell wall structure (including peptidoglycan type and teichoic acid presence) and G+C content of DNA in a range of 30-40 mol\%. The recommended minimal standards for describing a new Staphylococcus species are based on the results of phenotypic and genomic studies of at least five independently isolated strains. They include colony morphology and the results of the following conventional tests: pigment production, growth requirements, fermentative and oxidative activity on carbohydrates, novobiocin susceptibility, enzymic activities (nitrate reductase, alkaline phosphatase, arginine dihydrolase, ornithine decarboxylase, urease, cytochrome oxidase, staphylocoagulase in rabbit plasma, heat-stable nuclease, amidases, oxidases, clumping factor, and haemolytic activity on sheep or bovine blood agar). DNA-DNA hybridization experiments may distinguish species when the difference between the binding in the homologous reaction and the binding in the heterologous reaction expressed as a percentage is less than $70 \%$. In addition, rRNA signature sequence criteria, ribotyping characterization of the nomenclature type strain and other strains of the species, and reference strains of other species is recommended to describe the strains of the new species with sets of genetic attributes and reveal possible grouping errors. This proposal has been endorsed by the members of the Subcommittee on the taxonomy of staphylococci and streptococci of the International Committee on Systematic Bacteriology.
\end{abstract}

Keywords: minimal standards, staphylococcal species

\section{INTRODUCTION}

In accordance with Recommendation $30 \mathrm{~b}$ of the International Code of Nomenclature of Bacteria (Lapage et al., 1975), which calls for the development of minimal standards for describing new species, we propose minimal standards for the genus Staphy- lococcus, and for the description of new Staphylococcus species.

To gain some idea of the range of phenotypic variation of the strains and to make a pertinent choice in designating the type strain, we recommend that at least five independently isolated strains of the newly proposed species should be tested.

When culture media or reagents are commercialized by several companies, their origin is not given in the text. 


\section{RECOMMENDED MINIMAL TESTS AT THE GENUS LEVEL}

The minimal standards for assigning an organism to the genus Staphylococcus are divided between phenotypic criteria: Gram reaction; cell morphology; cell wall structure (peptidoglycan type and teichoic acid presence), aerobic and fermentative metabolism; catalase; motility and genotypic criteria; the appropriate DNA $\mathrm{G}+\mathrm{C}$ content, rRNA oligonuclotides sequencing.

\section{Phenotypic criteria}

A phenotypic description of a new species is crucial because this is how the bench worker who isolates the bacterium attains preliminary classification.

\section{Gram reaction and general morphology}

Smears for Gram staining should be prepared from $24 \mathrm{~h}$ cultures and examined for cell morphology, staining properties, size and aggregation patterns. Stained smears and living preparation (phase-contrast) of several strains should also be examined, at $4 \mathrm{~h}$ incubation intervals over a $36 \mathrm{~h}$ period, to check possible changes in cell morphology.

Cells of staphylococci appear as typical Gram-positive cocci by light microscopy, occurring singly, in pairs and irregular clusters (Holt et al., 1994). Cell diameters range from 0.5 to $1.5 \mu \mathrm{m}$ and cells do not form spores.

\section{Catalase}

A loopful of a culture is suspended in $2 \mathrm{ml}$ physiological saline. One millilitre of a $3 \% \mathrm{H}_{2} \mathrm{O}_{2}$ solution is then added to the cell suspension of staphylococci or micrococci and any bubbling is recorded as positive for catalase (Kloos \& Schleifer, 1975a). All species of staphylococci are catalase-positive with the exception of Staphylococcus aureus subsp. anaerobius, Staphylococcus saccharolyticus and some variant strains of other species in the genus (Schleifer, 1986).

\section{Motility}

Cultures from liquid and solid media are examined for motility under a phase-contrast microscope at low $(\times 100)$ and high $(\times 500)$ magnifications. Staphylococci are non-motile (Kloos \& Schleifer, 1975a).

\section{Aerobic and fermentative metabolism}

Unlike micrococci, staphylococci are not strict aerobes, but two species, Staphylococcus aureus subsp. anaerobius and Staphylococcus saccharolyticus, produce strains that do not grow aerobically.

Anaerobic growth in a glucose-containing medium. We recommend the use of semisolid thioglycolate medium as described by Evans \& Kloos (1972). The medium contains a total of $0.35 \%$ agar, glucose as an energy source, sodium thioglycolate to help maintain a low redox potential, and methylene blue as a redox indicator. One loopful of a $24 \mathrm{~h}$ culture in trypticase soy broth is transferred into a tube of the sterile test medium that has been steamed and cooled to $50^{\circ} \mathrm{C}$. After the inoculum is gently mixed with the loop, the medium is allowed to solidify at room temperature. An incubation temperature of $35^{\circ} \mathrm{C}$ is selected to provide a rapid response for the staphylococci. Overnight incubation is often sufficient; however, up to $72 \mathrm{~h}$ is required for some slow-growing cultures. The tubes are examined towards, but not directly at, a light source while slowly rotating the tube. The location and intensity of the zones of growth are recorded. Most species of staphylococci demonstrate moderate or good diffuse growth or colonies developing in the anaerobic portion.

\section{Cell wall structure}

The ultrastructure and chemical composition of the cell wall of staphylococci are typical for those of Gram-positive bacteria. Electron microscopy of suitably stained sections of the cell wall shows a thick $(30-60 \mathrm{~nm})$, rather homogeneous and less electrondense layer. It is made up of peptidoglycans, teichoic acids and proteins (Schleifer et al., 1976). Peptidoglycan typing assists generic identification in the case of some species of staphylococci such as Staphylococcus saccharolyticus and Staphylococcus aureus subsp. anaerobius that do not produce catalase and grow predominantly under aerobic conditions (Schleifer, 1986).

(i) Peptidoglycan type. Peptidoglycan (murein, mucopeptide) is a heteropolymer consisting of glycan chains which are cross-linked through short peptides (Schleifer et al., 1976). The composition and primary structure of the peptidoglycan of staphylococci and micrococci are quite different. The peptidoglycan of staphylococci contains an interpeptide bridge consisting of oligoglycine peptides, whereas no glycine is found within the interpeptide bridge of micrococci. The peptidoglycan of micrococci is often cross-linked by oligoalanine peptides or - as in the case of Micrococcus luteus - by polymerized peptide subunits.

Two relatively simple procedures can distinguish different peptidogycan types sufficiently clearly for comparative purposes. The first one is the determination of $\mathrm{N}$-terminal amino acids : dinitrophenylation from Takebe (1965). The second procedure uses a partial acid hydrolysis. Different types of peptidoglycan yield distinctive small peptide products on partial acid hydrolysis (peptidoglycan is hydrolysed in $4 \mathrm{M} \mathrm{HCl}$ at $100^{\circ} \mathrm{C}$ for periods ranging from 15 to $60 \mathrm{~min}$ ). Two-dimensional chromatography of these small peptides produces 'fingerprints' which are characteristic of the peptidoglycan types (Schleifer \& Kandler, 1972).

For total amino acid analysis, SDS-purified cell walls are hydrolysed with $4 \mathrm{M} \mathrm{HCl}$ for $16 \mathrm{~h}$ at $100^{\circ} \mathrm{C}$. The 
levels of amino acids are determined with an amino acid analyser. The peptidoglycan structure is deduced from the molar ratios of glutamic acid to glycine, Lalanine, L-serine, L-lysine, glucosamine and muramic acid, according to the procedure previously described by Schleifer \& Kandler (1972).

(ii) Presence of teichoic acid. Unlike micrococci, staphylococci contain teichoic acid in their cell wall.

\section{Additional tests}

Some tests are classified as additional tests because they are routinely not performed in all laboratories. They include glycerol acidification, determination of susceptibility to lysostaphin, lysozyme, furazolidone, bacitracin and vibriostatic compound $\mathrm{O} / 129$, menaquinone pattern, cellular fatty acids and fructose-1,6bisphosphate aldolase class I.

\section{Glycerol acidification}

This test is used because most staphylococci are able to produce acid aerobically from glycerol in the presence of $0.4 \mathrm{mg}$ erythromycin $\mathbf{1}^{-1}$ (Kloos \& Schleifer, 1975a; Schleifer \& Kloos, 1975b).

\section{Lysostaphin susceptibility}

Most staphylococci are susceptible to lysostaphin (200 $\mathrm{mg}^{-1}$ ) (Sigma).

An agar overlay is prepared by adding $0.1 \mathrm{ml}$ of a saline cell suspension (approx. $10^{7}$ c.f.u. $\mathrm{ml}^{-1}$ ) to a tube containing $3 \mathrm{ml}$ fluid, soft peptone/yeast extract/ glucose agar (0.75\% agar) (Kloos et al., 1974). After thorough mixing, the cell suspension in agar is poured onto the surface of a dry soft $\mathrm{P}$ agar plate. $\mathrm{P}$ agar is a non-selective isolation medium and has the following composition: peptone, $10 \mathrm{~g}$; yeast extract, $5 \mathrm{~g}$; sodium chloride, $5 \mathrm{~g}$; glucose, $1 \mathrm{~g}$; agar, $15 \mathrm{~g}$; distilled water, $1000 \mathrm{ml}$ ) (Naylor \& Burgi, 1956). A drop of sterile $200 \mathrm{mg}^{-1}$ lysostaphin solution is placed on the inoculated agar and incubated for $24-48 \mathrm{~h}$. Lysostaphin susceptibility is interpreted according to the following spot-inhibition scheme: + , sensitive (complete growth inhibition); \pm , slightly resistant (partial growth inhibition); and - , resistant (no visible growth inhibition). Susceptibility to lysostaphin can also be tested in $\mathrm{P}$ agar with paper disks containing 50, 75, 100 and $200 \mu \mathrm{g}$ lysostaphin (Kloos \& Schleifer, 1975b). Mueller-Hinton agar can be used as an alternative medium.

\section{Lysozyme susceptibility}

Staphylococci are resistant to lysozyme $\left(25 \mathrm{mg}^{-1}\right)$ (Sigma). Lysozyme susceptibility is determined on the same agar plate as used for testing lysostaphin. A drop of a sterile $400 \mathrm{mg} \mathrm{l}^{-1}$ lysozyme solution is placed on the surface of the inoculated agar plate. Lysozyme susceptibility is interpreted by using the same scheme described for the lysostaphin susceptibility (Kloos et al., 1974).

\section{Furazolidone, bacitracin and vibriostatic compound O/129 susceptibility}

Staphylococci are susceptible to furazolidone $(100 \mu \mathrm{g}$ disk) but are resistant to bacitracin $(0.04$ units) and to the vibriostatic compound $\mathrm{O} / 129$. Susceptibility to these compounds is tested by placing paper disks containing $100 \mu \mathrm{g}$ and $300 \mu \mathrm{g}$ furazolidone (Sigma), 0.02 and $0.04 \mathrm{U}$ bacitracin (Falk \& Guering, 1983), and $0.5 \mathrm{mg}$ vibriostatic compound $\mathrm{O} / 129$ (Bouvet et al., 1982) on inoculated Mueller-Hinton agar overlay plates (Acar \& Goldstein, 1986).

\section{Menaquinone pattern}

Like many other Gram-positive bacteria, staphylococci synthesize menaquinones, i.e. 2-methyl-3polyiso-prenyl-1,4-naphthoquinones, as their sole respiratory quinones (Collins \& Jones, 1981). Their isoprenoic side-chains are unsaturated whereas most micrococci possess partially hydrogenated menaquinones consisting of seven to nine isoprene units. Members of the genus Staphylococcus can be differentiated from closely related taxa by their quinone pattern, since most other Gram-positive cocci with low $\mathrm{G}+\mathrm{C}$ content completely lack isoprenoid quinones. Quinone systems are determined as reported previously (Collins, 1981; Collins et al., 1977; Tamaoka et al., 1983).

\section{Cellular fatty acids}

Staphylococci are easily differentiated from all other Gram-positive bacteria because they synthesize eicosanoic acid (C20:20) and octadecanoic acid (C18:0) in addition to the iso- and anteiso-branched fatty acids (Freney et al., 1991; Minnikin et al., 1979).

\section{Fructose-1,6-bisphosphate (FBP) aldolase class}

Another characteristic feature of most staphylococci is the occurrence of a class I FBP aldolase (Fischer et al., 1983; Götz et al., 1979, 1980). Most micrococci possess a class II FBP aldolase that contains an essential divalent cation whereas class I enzymes are found in animals and plants and form a Schiff-base intermediate. Class I aldolases can be inactivated with sodium borohydride, whereas class II enzymes are inhibited by chelating agents such as EDTA. The class of FBP aldolase is determined by the method of Götz et al. (1979).

\section{Genotypic criteria}

\section{$\mathbf{G}+\mathbf{C}$ content}

It is generally accepted that the $\mathrm{G}+\mathrm{C}$ content range for the genus Staphylococcus is between 30 and $40 \mathrm{~mol} \%$ (Kocur et al., 1971). Assignment to the 
genus Staphylococcus must be questioned if a strain or putative species is outside of that range, otherwise the data have no determinative power.

No particular method is recommended for release of high-molecular-mass DNA as different techniques have proven to be reliable. The $\mathrm{G}+\mathrm{C}$ content may be determined either by using melting temperature profiles, or by HPLC.

We recommend to use methods applied to systematics that are described in the Manual of Methods for General and Molecular Bacteriology (Gerhardt et al., 1994).

\section{rRNA oligonucleotide sequencing}

Phylogenetic relationships have been assessed at all taxonomic levels by reference sequence analysis of rRNA and/or of the gene that encodes it and provides arbitration of generic assignment. Sequencing of 16S rRNA and of 23S rRNA have great sensitivity. In addition, 5S rRNA sequence determination can be useful (Erdman et al., 1985), however there are limitations due to the small size of the macromolecule and the amount of information gained. Genes encoding 16S rRNA genes (16S rDNA) are amplified in vitro by using PCR. Primers directed to the extremities of the gene are used to amplify the target DNA. The amplified 16S rDNA fragment can either be sequenced directly or cloned into a plasmid or phage vector prior to sequencing. This is the method of choice for most rRNA gene sequencing since it provides a straightforward route to unambiguous DNA sequencing. Once generated, the sequences are aligned so that corresponding nucleotide sites are compared. Similarities between sequence pairs are determined, and an unrooted phylogenetic tree is constructed by using previously described methods. In the case of staphylococci, several methods have been used successfully by different authors (Hajek et al., 1992; Ludwig et al., 1990; Owen \& Pitcher, 1985; Saitou \& Nei, 1987; Schleifer et al., 1990).

\section{RECOMMENDED MINIMAL TESTS AT THE SPECIES LEVEL}

The recommended minimal standards for the description of a new staphylococcal species are based on the results of phenotypic and genomic studies.

As recommended by Wayne et al. (1987), a distinct genomospecies that cannot be differentiated from another genomospecies on the basis of any known phenotypic property should not be named until they can be differentiated by some phenotypic property.

\section{Phenotypic criteria}

Phenotypic criteria include colony morphology and the results of the following conventional tests: pigment production, growth requirements, fermentative and oxidative activity on carbohydrates, novobiocin susceptibility and enzymic activities (nitrate reductase,
Table 1. Recommended tests at the genus and the species level

GENUS LEVEL
Phenotypic criteria
Gram reaction and general morphology
Catalase
Motility
Aerobic and fermentative metabolism
Cell wall structure:
$\quad$ (i) Peptidoglycan type
$\quad$ (ii) Teichoic acid presence
Additional tests
Glycerol acidification
Lysostaphin susceptibility
Lysozyme susceptibility
Furazolidone, bacitracin and vibriostatic compound $\mathrm{O} / 129$
susceptibility
Menaquinone pattern
Cellular fatty acids
Fructose-1,6-bisphosphate aldolase class
Genotypic criteria
G+C content
rRNA oligonucleotides sequencing

\section{SPECIES LEVEL}

Phenotypic criteria

Growth requirements and characteristics:

Components and $\mathrm{pH}$ of the culture medium

Atmosphere

Temperature

Colony morphology

Pigment production

Novobiocin susceptibility determination

Fermentative and oxidative activity on carbohydrates

Enzymic activities:

(i) Nitrate reductase

(ii) Alkaline phosphatase

(iii) Arginine dihydrolase

(iv) Ornithine decarboxylase

(v) Urease

(vi) Cytochrome oxidase

(vii) Staphylocoagulase

(viii) Clumping factor or fibrinogen-affinity factor

(ix) Heat-stable nuclease

(x) Haemolytic activity on sheep or bovine and human blood agar

Additional tests

Additional carbohydrates

Fermentation product profiles (DL-lactic acid)

Acetoin production

Fosfomycin susceptibility

Enzymic activities:

(i) Splitting of Tween 80

(ii) Lecithinase

(iii) Fibrinolysin or staphylokinase

(iv) $\beta$-galactosidase, $\beta$-glucuronidase ...

Susceptibility to other antibiotics, heavy metals \& antiseptics

Haemolysins

Staphylolytic activity

Cytoplasmic membrane analysis:

(i) Teichoic acid type

(ii) Cellular fatty acids

(ii) Polar lipids

(iii) Cytochrome patterns

Total protein profiles

Protein A

Genotypic criteria

DNA-DNA hybridization

$\Delta T_{\mathrm{m}}$

Additional test

Ribotyping 
alkaline phosphatase, arginine dihydrolase, ornithine decarboxylase, urease, cytochrome oxidase, staphylocoagulase in rabbit plasma, heat-stable nuclease, amidases, oxidases, clumping factor, and haemolytic activity on sheep or bovine blood agar) (Tables 1 and 2).

\section{Growth requirements and characteristics}

Staphylococci are heterotrophic and require complex media for growth.

Components and $\mathrm{pH}$ of the culture medium. Growth in the presence of $0,5,7.5,10$ and $15 \% \mathrm{NaCl}$ in $\mathrm{P}$ agar (Kloos et al., 1974) should be estimated by culturestreak development after an incubation of $48 \mathrm{~h}$ at $30{ }^{\circ} \mathrm{C}$. Streaks are made by lightly inoculating a $1 \mathrm{~cm}$ line on the surface of an agar plate with a loopful of a culture.

The ability of strains to grow on inorganic nitrogen is estimated by using a defined agar medium containing $\mathrm{NH}_{4} \mathrm{H}_{2} \mathrm{PO}_{4}$ and $\mathrm{NH}_{4} \mathrm{Cl}$ as the only sources of nitrogen. The complete description of this medium is given by Kloos \& Wolfshohl (1979). The relative percentage of growth on the inorganic nitrogen agar to that on $\mathrm{P}$ agar is estimated by a ratio $I / P \times 100$ where $I$ is the mean colony diameter on the inorganic nitrogen agar and $P$ is the mean colony diameter on $\mathrm{P}$ agar. The results of this test has been used later as the basis for nutritional studies on amino acid and vitamin requirements.

Atmosphere. Aerobic requirement of each strain is estimated by using the semisolid thioglycolate medium described by Evans \& Kloos (1972). A loopful of a culture is suspended in $2 \mathrm{ml}$ physiological saline. A $0.1 \mathrm{ml}$ sample (approx. $10^{7}$ c.f.u.) of the cell suspension is then used to inoculate a tube containing $8 \mathrm{ml}$ fluid $\left(52^{\circ} \mathrm{C}\right)$ thioglycolate medium. Inoculated tubes are allowed to solidify at room temperature and are then incubated for $5 \mathrm{~d}$. Growth characteristics are noted at the end of the incubation period.

Temperature. Growth on $\mathrm{P}$ agar at 15 and $45^{\circ} \mathrm{C}$ should be estimated by culture-streak development after incubation for $48 \mathrm{~h}$. The optimal temperature should be determined.

\section{Colony morphology}

Strain identity should at least start with good characterization of colony morphology. The best method allows well-isolated colonies to develop over a period of $3 \mathrm{~d}$ at incubation temperatures of $30-35^{\circ} \mathrm{C}$ on freshly prepared $\mathrm{P}$ agar (Kloos et al., 1991), tryptic soy agar (TSA), and TSA supplemented with $5 \%$ sheep blood and then a further $2 \mathrm{~d}$ at room temperature (Kloos \& Bannerman, 1994; Kloos \& Schleifer, $1975 b$ ). Colonial characteristics, including profile, edge, surface texture, and pigment, are recorded daily throughout the incubation period. The diameters of five widely isolated colonies are measured at the end of the incubation period $(5 \mathrm{~d})$.

\section{Pigment production}

Because use of media containing fatty acids or milk enhances pigment production (Willis et al., 1966), pigmentation should be tested on agar with $30 \%$ fullfat milk, and on egg yolk agar. Plate cultures are incubated for $24 \mathrm{~h}$ at $37^{\circ} \mathrm{C}$, and then for $3 \mathrm{~d}$ at room temperature.

\section{Novobiocin susceptibility determination}

The MIC of novobiocin for recognized staphylococcal species has been previously determined (Kloos \& Schleifer, 1975b). We recommend that susceptibility of strains to $1.6 \mu \mathrm{g}$ novobiocin per $\mathrm{ml} \mathrm{P}$ agar should only be determined. The procedure is the same as that described for lysostaphin.

\section{Fermentative and oxidative activity on carbohydrates}

According to the most recent edition of the Bergey's Manual of Systematic Bacteriology (Schleifer, 1986), oxidation and fermentation of D-glucose and Dmannitol, and ability to aerobically produce acid at least from L-arabinose, D-xylose, D-cellobiose, Dfucose, raffinose, salicin, sucrose, maltose, D-mannose, $\mathrm{D}$-trehalose, $\alpha$ lactose, $\mathrm{D}$-galactose, $\beta$-D-fructose, $\mathrm{D}$ melezitose, D-turanose, D-ribose and xylitol should be examined.

Acid production from various carbohydrates is detected under aerobic conditions using an agar plate method. Each carbohydrate agar is prepared by adding an appropriate sample of a filter-sterilized carbohydrate stock solution to an autoclave-sterilized purple agar base medium (Difco). The final carbohydrate concentration is $1 \%$ in the agar medium. Culture streaks are made by lightly inoculating a $1 \mathrm{~cm}$ line on the surface of an agar plate with a loopful of cells. Reactions are interpreted according to the following scheme: + , moderate to strong acid (yellow indicator colour extends out from the culture streak into the surrounding medium within $72 \mathrm{~h}$ ); \pm , weak acid (distinct yellow indicator colour under culture streak, but not extending into the surrounding medium within $72 \mathrm{~h}$ ); - , no acid (very faint to no yellow indicator colour under the culture streak within $72 \mathrm{~h}$ ). Strong acid production is generally detected within $24 \mathrm{~h}$, and moderate acid production by most strains is detected within 48-72 h (Kloos \& Schleifer, 1975b).

\section{Enzymic activities}

(i) Nitrate reductase. Nitrate reduction is tested by the sulfanilic acid and $\alpha$-naphthylamine method, and confirmed with zinc dust (Cowan \& Steel, 1965). A loopful of a culture is suspended in $5 \mathrm{ml}$ nitrate broth to obtain a density of approximately $10^{7}$ c.f.u. $\mathrm{ml}^{-1}$. The inoculated broth tubes are shaken vigorously in a $34{ }^{\circ} \mathrm{C}$ water bath for $48 \mathrm{~h}$ and examined. The colour is developed by adding five drops of sulfanilic acid reagent $[0.8 \%(\mathrm{v} / \mathrm{v})$ in $5 \mathrm{M}$ acetic acid] and five drops 


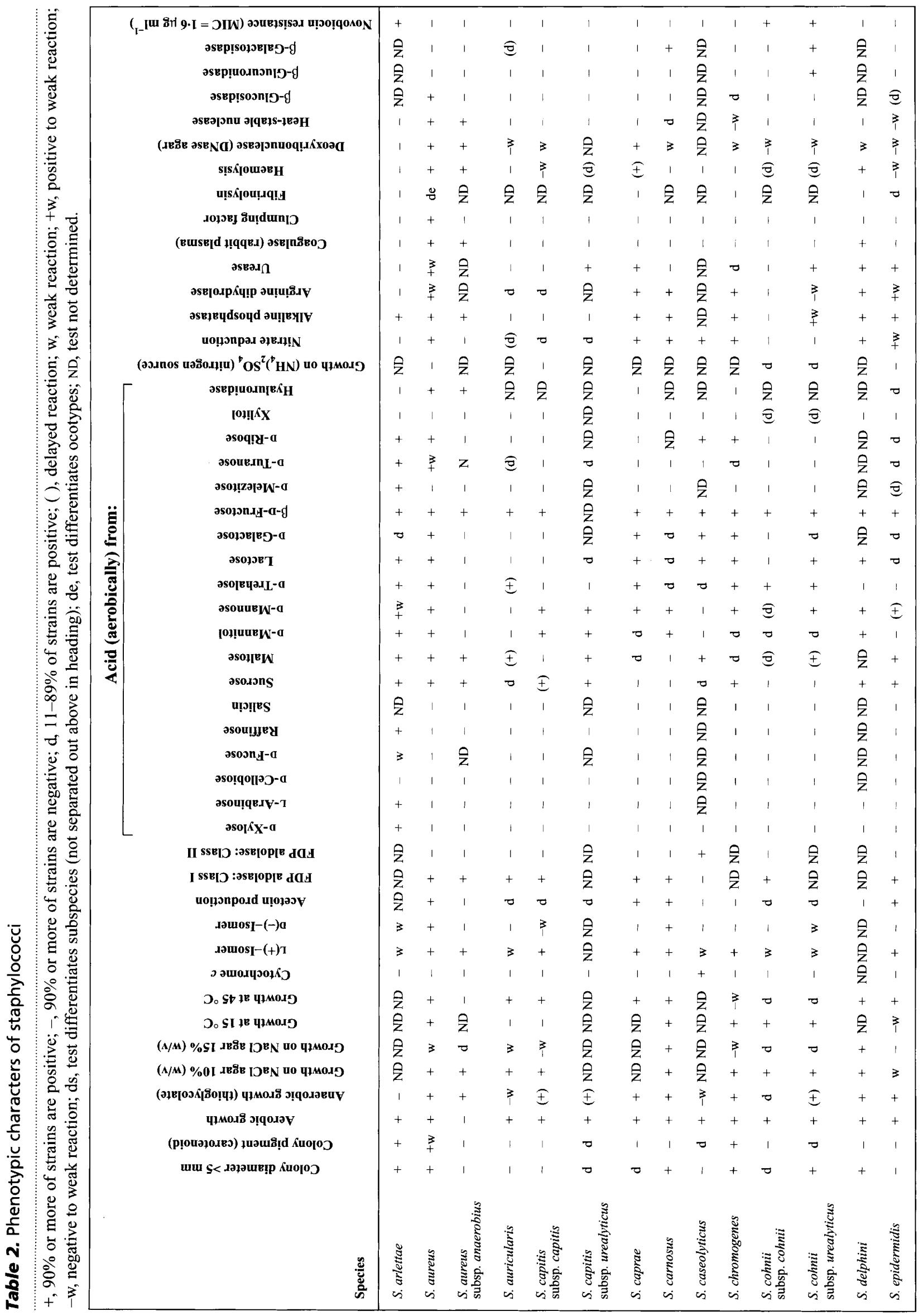




\begin{tabular}{|c|c|c|c|c|c|c|c|c|c|c|c|c|c|c|c|c|c|c|c|c|c|c|c|c|}
\hline+ & 1 & + & 1 & & & 1 & + & + & 1 & t & & & & & & & & 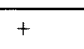 & & + & & + & & \\
\hline $\mathrm{Z}$ & + & 3 & 1 & 1 & 1 & s8 & $\hat{z}$ & 1 & 1 & + & & 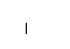 & 1 & $\hat{z}$ & $\nabla$ & + & $\nabla$ & 1 & & 1 & + & 吕 & & \\
\hline $\mathrm{z}$ & 1 & 1 & $\theta$ & 1 & 0 & 1 & $\hat{\mathrm{z}}$ & 1 & 1 & z & z & 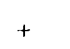 & । & $\hat{z}$ & 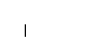 & 1 & & 1 & 1 & 1 & $\theta$ & $\frac{1}{2}$ & $\theta$ & \\
\hline$\overline{\mathrm{z}}$ & 1 & + & $\nabla$ & 1 & $\nabla$ & $\nabla$ & $\hat{\bar{z}}$ & + & 会 & + & $\overrightarrow{\mathrm{z}}$ & + & + & $\hat{\mathrm{z}}$ & $\nabla$ & $\nabla$ & z & + & + & + & I & 0 & + & \\
\hline 1 & 3 & 1 & 1 & 1 & + & + & 1 & 会 & 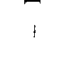 & $\mathrm{z}$ & 1 & 1 & $\hat{z}$ & $\hat{\mathrm{z}}$ & 1 & 1 & + & 1 & 1 & 1 & $\beta_{1}$ & $\hat{z}$ & 1 & \\
\hline 1 & $\hat{z}$ & $\hat{z}$ & $y$ & 3 & + & + & 1 & $\begin{array}{l}4 \\
3 \\
+\end{array}$ & 安 & + & 1 & 1 & $\hat{z}$ & $\hat{z}$ & 1 & 1 & 主 & & & & 3 & z & 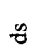 & \\
\hline 0 & 3 & 3 & I & 3 & 1 & $\sigma$ & $=$ & 1 & $\geqslant$ & + & 3 & $\mathrm{z}$ & $i$ & 1 & 1 & 1 & $\overline{3}$ & $\stackrel{3}{+}$ & 3 & $\vec{D}$ & 3 & 3 & 预 & $\uparrow$ \\
\hline I & $\mathrm{z}$ & & z & $\hat{z}$ & 0 & 1 & 1 & 安 & 1 & 之 & 1 & 1 & 之 & $\hat{z}$ & z & - & 1 & & & & 会 & 穴 & $\hat{z}$ & $\hat{z}$ \\
\hline 1 & 1 & I & 1 & 1 & 1 & $\theta$ & 1 & 1 & + & 1 & 1 & 1 & $\hat{z}$ & 1 & & . & + & 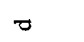 & + & 1 & & 1 & & \\
\hline ' & 1 & 1 & 1 & 1 & $\sigma$ & + & 1 & 1 & 1 & + & 1 & 1 & $\overline{1}$ & 1 & I & 1 & 1 & 1 & 1 & 1 & 1 & 1 & & 1 \\
\hline+ & + & + & 1 & + & $\nabla$ & + & $\nabla$ & 1 & 0 & + & 1 & + & + & 之 & + & + & 1 & 1 & 1 & 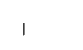 & + & $\mathrm{z}$ & + & + \\
\hline | & + & 1 & + & $\theta$ & + & $n$ & 1 & 1 & 1 & 1 & 1 & । & + & + & 3 & 1 & + & 1 & 1 & & + & $\hat{z}$ & ס & \\
\hline+ & + & + & 1 & 1 & + & + & + & 3 & 1 & + & + & 1 & + & 立 & : & & + & 0 & $\nabla$ & & 3 & 1 & & \\
\hline+ & + & + & $\theta$ & 0 & + & + & 1 & + & + & + & 安 & 之 & + & + & 1 & + & + & + & & & + & + & 3 & 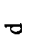 \\
\hline$\widehat{\mathrm{z}}$ & そ & 令 & 1 & 1 & 会 & 1 & 会 & + & 立 & $\hat{z}$ & 命 & $\hat{z}$ & 会 & 学 & $\nabla$ & 0 & 之 & 会 & 乏 & & & z & & + \\
\hline 1 & 1 & 1 & 令 & $\hat{z}$ & + & 云 & 1 & z & 之 & 1 & 会 & $\hat{z}$ & 定 & 会 & $\hat{z}$ & $\hat{z}$ & 文 & & & z & 令 & $\hat{z}$ & 完 & 文 \\
\hline ' & 1 & $\nabla$ & 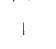 & 1 & 1 & 1 & $\geqslant$ & 1 & 1 & $\mathrm{z}$ & $\hat{\mathrm{z}}$ & 1 & 1 & 1 & 0 & & 1 & 1 & 1 & & 1 & 安 & & 3 \\
\hline+ & 3 & + & $\nabla$ & 1 & + & + & + & + & 1 & 至 & 1 & 1 & 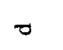 & 文 & . & . & 1 & + & + & & 0 & + & ס & r \\
\hline 0 & $\mathrm{z}$ & + & 0 & $\sigma$ & 1 & 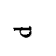 & 3 & 1 & 0 & 安 & + & $\mathrm{z}$ & 1 & z & + & 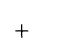 & 1 & $\mathrm{z}$ & z & & & 1 & & \\
\hline+ & 1 & + & 1 & D & 1 & 1 & $\stackrel{3}{+}$ & 1 & 令 & 它 & 1 & $\mathrm{z}$ & + & 会 & 1 & & z & 1 & & 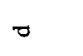 & 1 & z & $y$ & \\
\hline+ & + & + & $\nabla$ & + & + & + & $\begin{array}{l}+ \\
+\end{array}$ & 玉 & + & z & + & 台 & 会 & $\underset{ \pm}{ \pm}$ & + & + & 3 & + & + & + & + & 气 & + & + \\
\hline+ & 0 & + & 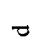 & ه & + & + & $\underset{+}{3}$ & 0 & 号 & + & 1 & + & + & $\hat{z}$ & 1 & 玉 & z & & & $£$ & 3 & $\bar{z}$ & $\nabla$ & 8 \\
\hline$\nabla$ & + & 0 & $\nabla$ & $\overrightarrow{0}$ & + & $\sigma$ & $\nabla$ & 0 & + & + & 1 & 令 & $\theta$ & 1 & $\nabla$ & & $\overline{1}$ & $\theta$ & 1 & $\uparrow$ & + & $\overline{\mathrm{z}}$ & $\ddot{z}$ & 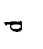 \\
\hline+ & + & + & + & 0 & + & + & + & + & + & + & + & + & + & I & + & + & ס & + & + & & $\nabla$ & $\widehat{0}$ & & $f$ \\
\hline+ & + & + & 1 & 1 & + & + & 1 & 王 & + & + & 1 & I & 1 & $\mp$ & & & + & $=$ & + & & 0 & 1 & & $T$ \\
\hline+ & $\nabla$ & + & $\nabla$ & 1 & 1 & 의 & + & + & 1 & + & 1 & 3 & 0 & I & $\nabla$ & & & & & & + & 立 & 0 & $\nabla$ \\
\hline+ & 1 & + & + & + & 1 & $\widehat{3}$ & + & $\nabla$ & + & + & 1 & 3 & 0 & I & + & + & 1 & $\stackrel{3}{+}$ & อ & อ & $\beta$ & 1 & 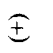 & + \\
\hline+ & $\partial$ & + & + & & + & + & 1 & + & + & 号 & + & + & $\theta$ & 1 & + & + & 1 & + & + & + & + & $\hat{z}$ & + & + \\
\hline 吾 & 1 & + & 1 & 1 & 1 & 1 & z & 0 & z & $\hat{z}$ & 1 & $\hat{z}$ & 1 & $\hat{z}$ & 1 & & 之 & 0 & $\nabla$ & + & 1 & 1 & & כ \\
\hline 1 & 1 & + & 1 & 1 & 1 & 1 & 1 & + & 1 & $\mathrm{z}$ & 1 & 1 & 1 & $\mathrm{z}$ & 1 & & & & & & & 1 & & \\
\hline 1 & 立 & 3 & 1 & 1 & 1 & 1 & 1 & 0 & 学 & $\mathrm{z}$ & 1 & $\mathrm{z}$ & 1 & $\mathrm{z}$ & I & & $\hat{z}$ & + & $\nabla$ & + & 1 & z & & \\
\hline 3 & 1 & + & । & 1 & 1 & 1 & 1 & + & 1 & $\widehat{\hat{z}}$ & 1 & I & 1 & I & । & I & 1 & $\nabla$ & $\nabla$ & + & 1 & (ิ) & 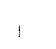 & \\
\hline+ & 1 & + & 1 & 1 & 1 & 1 & 0 & 0 & 1 & $\overline{\mathrm{z}}$ & 1 & 1 & 1 & 1 & 1 & 1 & 1 & $\nabla$ & $\nabla$ & 1 & 1 & 1 & 1 & + \\
\hline+ & 1 & + & 1 & 1 & 1 & 1 & 1 & 3 & 1 & + & + & 1 & 1 & & 1 & & 1 & + & 0 & $\delta$ & 1 & 오 & & + \\
\hline $\mathrm{z}$ & 之 & 1 & 1 & 1 & + & + & $\hat{\mathrm{z}}$ & 1 & 之 & z & $\hat{z}$ & 羊 & 旦 & & & & 之 & z & z & & & z & & \\
\hline ż & 会 & + & + & + & + & + & 宗 & + & 完 & 完 & 会 & 会 & $\hat{z}$ & + & & & 合 & z & 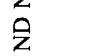 & & & 弁 & & + \\
\hline$\hat{z}$ & 1 & 1 & $\nabla$ & ه & 1 & 1 & 完 & 1 & + & + & 1 & 3 & $\hat{\mathrm{z}}$ & 立 & + & & + & 3 & 3 & \} & 3 & 会 & & \\
\hline 3 & 号 & 1 & + & + & 1 & 1 & 3 & 1 & + & $\hat{z}$ & 学 & $\hat{z}$ & 会 & 1 & 3 & & 3 & z & 之 & 1 & $\nabla$ & 云 & + & T \\
\hline$\geqslant$ & $\hat{2}$ & + & 1 & $\theta$ & + & + & 3 & + & 3 & $\hat{\mathrm{z}}$ & $\overline{\mathrm{z}}$ & $\hat{\mathrm{z}}$ & 号 & 3 & 3 & & + & z & z & + & + & 会 & + & 3 \\
\hline 1 & 1 & 1 & 1 & 1 & 1 & 1 & 1 & + & 1 & 1 & 1 & 1 & 1 & 1 & 1 & & 1 & + & + & + & 1 & + & 1 & \\
\hline 1 & + & $\stackrel{z}{+}$ & + & + & 3 & + & 之 & 1 & + & + & 1 & + & $\hat{z}$ & + & 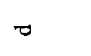 & & + & 3 & 3 & $z_{1}$ & + & $\hat{z}$ & & 1 \\
\hline 宜 & $\ddot{3}$ & 令 & 3 & 3 & + & + & ฉ & 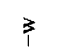 & z & そ & 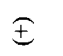 & + & $\mathrm{z}$ & & & & z & 之 & & & & 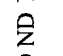 & & \\
\hline 会 & $\begin{array}{l}+ \\
+\end{array}$ & 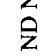 & 0 & 1 & 3 & 0 & 安 & 3 & + & 1 & + & + & + & $\mathrm{z}$ & $=$ & & & & & 0 & 3 & 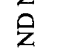 & & $=$ \\
\hline$\hat{z}$ & + & 令 & + & 3 & + & + & z & + & + & + & + & + & 乏े & 字 & + & & + & $\overline{\mathrm{z}}$ & $\overline{\mathrm{z}}$ & + & + & $\overline{\mathrm{z}}$ & + & + \\
\hline 1 & + & + & 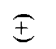 & 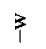 & + & $\mp$ & 1 & 3 & + & + & + & + & + & + & 玉 & & + & $\geqslant$ & 3 & $\frac{3}{+}$ & + & 1 & + & ס \\
\hline+ & + & + & + & + & + & + & + & + & + & + & + & + & + & 3 & + & r & + & + & + & + & + & + & + & + \\
\hline 1 & 1 & 0 & 0 & 0 & 1 & 1 & $\nabla$ & 0 & $\theta$ & I & 1 & 3 & + & 1 & r & + & 1 & $\nabla$ & $\nabla$ & $\nabla$ & 1 & + & $\nabla$ & D \\
\hline+ & + & + & + & 1 & + & + & + & 1 & 1 & 1 & + & + & z & 1 & + & 1 & 1 & 1 & 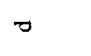 & $\nabla$ & + & 1 & $\nabla$ & + \\
\hline 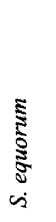 & $\stackrel{3}{5}$ & 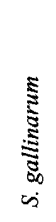 & 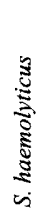 & 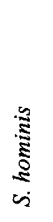 & 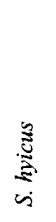 & 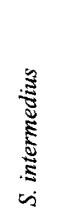 & 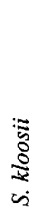 & 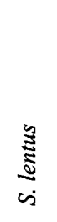 & 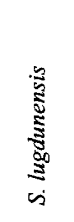 & 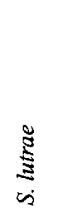 & $\begin{array}{l}\text { 苟 } \\
\text { है } \\
\text { is }\end{array}$ & 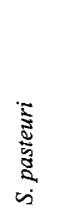 & 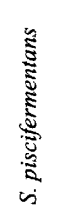 & 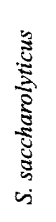 & 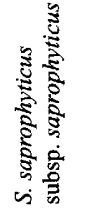 & 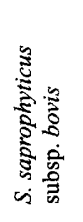 & 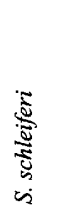 & 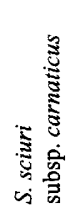 & 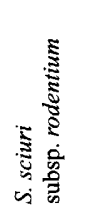 & 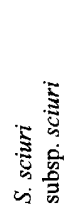 & 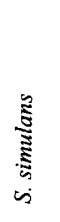 & 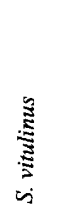 & 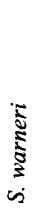 & \\
\hline
\end{tabular}


of $\alpha$-naphthylamine reagent [0.5\% (v/v) in $5 \mathrm{M}$ acetic acid], to the broth culture and is recorded after $2 \mathrm{~min}$. Colour test reactions are interpreted according to the following scheme: + , moderate to strong reaction (development of red-purple colour); \pm , weak reduction (development of pink colour); - , no reduction (no distinct colour change but red colour is produced after the addition of zinc dust) (Kloos \& Schleifer, 1975b).

(ii) Alkaline phosphatase. Phosphatase activity is determined by modification of the technique of Pennock \& Huddy (1967) proposed by Kloos \& Schleifer (1975b). All glassware used in the test are rinsed thoroughly with deionized water to remove any contaminating phosphates. Tubes containing $0.5 \mathrm{ml}$ buffer $(0.005 \mathrm{M}$ solution of phenolphthalein monophosphate in $0.01 \mathrm{M}$ citric acid/sodium citrate buffer $\mathrm{pH} 5.8$ ) are inoculated with a loopful of a culture to a density of $10^{7}$ c.f.u. $\mathrm{ml}^{-1}$. After incubation at $37^{\circ} \mathrm{C}$ for $4 \mathrm{~h}$, the reaction is stopped by adding $0.5 \mathrm{ml} 0.5 \mathrm{M}$ sodium hydroxide and $0.5 \mathrm{ml} 0.5 \mathrm{M}$ sodium bicarbonate. The colour is developed by adding $0.5 \mathrm{ml}$ 4-aminoantipyrine solution $(0.6 \mathrm{~g}$ per $100 \mathrm{ml})$ and $0.5 \mathrm{ml}$ potassium ferricyanide solution $(2.4 \mathrm{~g}$ per $100 \mathrm{ml})$. Colour test reactions are interpreted according the following scheme: + , moderate to strong activity (development of moderate to intense red colour); \pm , weak activity (development of pink colour); - , no activity (colour remains yellow).

(iii) Arginine dihydrolase. Arginine dihydrolase activity is performed in tubes containing Moeller medium (Moeller, 1955), both with and without a covering layer of sterile paraffin oil. Readings are recorded daily for $5 \mathrm{~d}$. Development of a violet colour is recorded as a positive result.

(iv) Ornithine decarboxylase. Ornithine decarboxylase activity is determined using a modification of the test of Moeller (Moeller, 1955) as described by Kloos \& Lambe (1991). Decarboxylase basal medium is prepared with $1 \%(\mathrm{w} / \mathrm{v})$ L-ornithine dihydrochloride and the final medium is adjusted to $\mathrm{pH} 6$ with $1 \mathrm{M}$ sodium hydroxide before sterilization. The medium is dispensed in $3-4 \mathrm{ml}$ amounts in small $(13 \times 100 \mathrm{~mm})$ screw-cap tubes and autoclaved at $121^{\circ} \mathrm{C}$ for $10 \mathrm{~min}$. A loopful of an overnight agar-slant culture of several well-isolated colonies are dispersed in the test broth, followed by overlaying each tube with $4-5 \mathrm{~mm}$ of sterile mineral oil. Inoculated tubes should be incubated at $35-37^{\circ} \mathrm{C}$ for up to $24 \mathrm{~h}$. A positive reaction is indicated by alkalinization of the medium, with a change in the initial greyish colour or slight yellowing (caused by the initial fermentation of glucose) to violet (caused by decarboxylation of L-ornithine). A yellow colour after $24 \mathrm{~h}$ incubation indicates a negative result.

(v) Urease. Urease activity is tested on Christensen agar (Christensen, 1946) and in a medium containing $1 \mathrm{~g}$ peptone $1^{-1}, 1 \mathrm{~g}$ glucose $1^{-1}, 5 \mathrm{~g}$ sodium chloride $\mathrm{l}^{-1}$, $1.2 \mathrm{~g}$ disodium phosphate $1^{-1}, 0.8 \mathrm{~g}$ potassium dihydrogen phosphate $\mathrm{l}^{-1}, 0 \cdot 012 \mathrm{~g}$ phenol red $\mathrm{l}^{-1}$ and
$15 \mathrm{~g}$ agar $1^{-1}$. After $3 \mathrm{~d}$ incubation at $35^{\circ} \mathrm{C}$, the purple-red colour of inoculated agar, is interpreted as a positive result (Faller \& Schleifer, 1981).

(vi) Cytochrome oxidase. Oxidase activity is estimated by dropping $1 \%$ tetramethyl-p-phenylenediamine dihydrochloride onto a plate culture. A blue-violet colour appearing within a few seconds in the colonies is read as a positive result. A modified test using a $6 \%$ solution of tetramethyl- $p$-phenylenediamine in DMSO is recommended by Faller \& Schleifer (1981).

(vii) Staphylocoagulase. The tube coagulase reaction is performed in fresh sodium citrate rabbit, human and bovine plasma, according to the recommendation of the ICSB Subcommittee on the Taxonomy of Staphylococci and Micrococci (1965). An alternative method is currently performed in routine laboratories and uses reconstituted lyophilized citrated rabbit plasma. The bacteria are inoculated in brain-heart infusion and incubated for $18-24 \mathrm{~h}$ at $37^{\circ} \mathrm{C}$. Reactions are carried out in a sterilized tube, according to the manufacturer's instructions. For example, $0.5 \mathrm{ml}$ of the rabbit plasma dilution is mixed with $0.5 \mathrm{ml}$ of the culture broth of the Staphylococcus strain to be tested. The tubes are shaken and placed at $37^{\circ} \mathrm{C}$ in an incubator or a waterbath. Readings are made after 1 and $4 \mathrm{~h}$ incubation at $37^{\circ} \mathrm{C}$, and then after $24 \mathrm{~h}$ in negative cultures of food and sources after 48 , and $72 \mathrm{~h}$ at room temperature. Gelatinous or solid coagulates are interpreted as positive, and flaky or fibrous clots are interpreted as weakly positive.

(viii) Clumping factor or fibrinogen-affinity factor. Clumping factor is identified by the method described by Cadness-Graves et al. (1943). This test should not be made with colonies taken directly from selective media. The suspected colonies should be subcultured on non-selective agar media or DNase agar in Petri dishes. For testing, a heavy bacterial suspension should be prepared in a loopful of saline and added to fresh sodium citrate rabbit plasma on a glass slide (Devriese \& Hajek, 1980). Formation of visible clusters within $60 \mathrm{~s}$ is regarded as a positive result. False-negative or delayed-positive results may occur when the test suspensions are too dilute. Dubious reactions can be clarified by the addition of more cells, with good mixing, into the reaction mixture.

Alternative methods for the slide test include commercial haemagglutination tests for clumping factor and commercial latex agglutination tests that detect both clumping factor and protein A (Kloos \& Lambe, 1991).

(ix) Heat-stable nuclease. Heat-stable nuclease is detected by the metachromatic agar-diffusion method of Lachica et al. (1971) using DNA and toluidine blue. After 2-, 4- and $24 \mathrm{~h}$ incubation periods, pink haloes produced around the wells filled with boiled broth cultures indicate nuclease activity.

(x) Haemolytic activity on sheep or bovine and human blood agar. Differences in the haemolytic activities of species 
are best demonstrated with bovine agar $(5 \%$ blood in $\mathrm{P}$ agar) and secondly with human blood agar. Streaks of cultures are made by lightly inoculating a $1 \mathrm{~cm}$ line on the surface of a blood agar plate with a loopful of cells. Haemolysis is characterized after 24,48 and $72 \mathrm{~h}$ incubation at $37^{\circ} \mathrm{C}$ and is interpreted according the following scheme: + , strong (haemolysis extending to $1.5 \mathrm{~mm}$ on bovine blood or to $2.5 \mathrm{~mm}$ on human blood, from the culture streak within $48-72 \mathrm{~h}$ ); \pm , moderate to weak (trace haemolysis or extending $<1.5 \mathrm{~mm}$ on bovine blood, $<2.5 \mathrm{~mm}$ on human blood from the culture streak within $72 \mathrm{~h}$ ); - , no clearly detectable haemolysis within 72 h (Kloos \& Schleifer, 1975b).

Conventional methods should be used for the determination of fermentative/oxidative and enzymic activities. However, alternatively available validated reagents or rapid methods could be used.

\section{Additional tests}

These tests may be required if there is not sufficient phenotypic distinction.

\section{Additional carbohydrates}

According to recently described staphylococcal species (Kloos \& Bannerman, 1994, 1995), the following carbohydrates should be added to the above list: Dmelibiose, L-rhamnose, $N$-acetylglucosamine and aesculin.

\section{Fermentation product profiles (DL-lactic acid)}

The procedure for determining the type of lactic acid produced has been previously described (Owen \& Pitcher, 1985). Organisms are grown in yeast extract/ peptone/glucose broth under microaerophilic or anaerobic conditions. They are incubated at $34^{\circ} \mathrm{C}$ for $5-6 \mathrm{~d}$. The type of lactic acid produced is determined enzymically with L-lactate dehydrogenase from rabbit muscle and D-lactate dehydrogenase obtained from Leuconostoc mesenteroides (Schleifer \& Kloos, 1975a).

\section{Acetoin production}

A modification of the method of Davis \& Hoyling, (1973) can be used for the acetoin test (Devriese \& Hajek, 1980). Petri dishes containing brain-heart infusion agar supplemented after autoclaving by $1 \%$ (w/v) glucose, are prepared. Four strains are patchinoculated onto each plate. After $24 \mathrm{~h}$ incubation at $37^{\circ} \mathrm{C}$, an antibiogram-type paper disk freshly soaked in a $10 \%$ sodium pyruvate solution is placed on each growth patch. The plates are incubated again for a further $3 \mathrm{~h}$. Thereafter, one drop of $40 \%(\mathrm{w} / \mathrm{v})$ potassium hydroxide, one drop of $1 \%(\mathrm{w} / \mathrm{v})$ creatine and one drop of an alcoholic solution of $1 \%(\mathrm{w} / \mathrm{v}) \alpha-$ naphthol are spotted successively on each disc. The development of a pink or red colour within $1 \mathrm{~h}$ indicates a positive result.

\section{Fosfomycin susceptibility}

Staphylococcus saprophyticus is the only described staphylococcal species that exhibits a natural resistance to fosfomycin (Loulergue et al., 1984).

\section{Enzymic activities}

(i) Splitting of Tween 80. Lipase activity is demonstrated in blood agar base enriched with $0.01 \% \mathrm{CaCl}_{2} .2 \mathrm{H}_{2} \mathrm{O}$ and $1 \%$ Tween 80 (Sierra, 1957). Splitting of Tween 80 is characterized by an opacity around the culture after $18 \mathrm{~h}$ incubation at $37^{\circ} \mathrm{C}$ and after $24 \mathrm{~h}$ incubation at room temperature.

(ii) Lecithinase. In addition, lecithinase is examined on Baird-Parker medium containing 5\% egg-yolk emulsion. After $2 \mathrm{~d}$ incubation at $37^{\circ} \mathrm{C}$ the lecithinase activity is characterized by a turbid ring around the growth area (Sierra, 1957).

(iii) Fibrinolysin or staphylokinase. Fibrinolysin production is investigated by the method of Christie \& Wilson (1941) but, instead of rabbit plasma, fibrinogen $(0.1 \mathrm{~g}$ fibrinogen per $100 \mathrm{ml}$ agar base) is used (Hajek, 1976). Fibrinogen is denatured in a water-bath at $55^{\circ} \mathrm{C}$ for $15 \mathrm{~min}$. Furthermore, the non-specific effect of proteinases is eliminated by addition of a polyvalent protease inhibitor. A strip $(1 \times 8 \mathrm{~cm})$ of Whatman no. 1 filter paper saturated with inhibitor (2000 trypsin inhibitory units $\mathrm{ml}^{-1}$ ) is placed on the medium and the cultures are inoculated perpendicularly to the strip. After $24 \mathrm{~h}$ incubation, partial inhibition of activity is regarded as a positive result. A complete lysis of fibrin around the inoculation streaks signifies a non-specific reaction.

It is necessary to distinguish between the specific staphylokinase effect which causes direct fibrinolysis, from indirect fibrinolysis effects due to bacterial proteases. We advise the use of purified fibrinogen and protease inhibitors.

\section{Susceptibility to other antibiotics, heavy metals and antiseptics}

Some Staphylococcus species and subspecies behave differently under antibiotic pressure. This variation has led to the recognition of certain interesting species and subspecies patterns. For example, Staphylococcus cohnii and Staphylococcus xylosus have been shown to be intrinsically resistant to lincomycin (Kloos, 1980). Thus, the MICs of numerous different agents (antibiotics, chemotherapeutics and disinfectants) should be determined by using the dilution micromethod with Mueller-Hinton broth (Hajek et al., 1996).

\section{Haemolysins}

The production of $\alpha$ - and $\beta$-haemolysins (with sheep erythrocytes) and $\delta$-haemolysins (with human erythrocytes) may be determined. Blood cells are washed with phosphate saline buffer ( $\mathrm{pH} 7 \cdot 2)$ and added to blood agar base to a final concentration of 
$2.5 \% . \quad \alpha$ - and $\beta$ - haemolysins, which behave antagonistically, are demonstrated by the "serumunmasking test' of Marica et al. (1974). Specific serum against antagonistic haemolysin is left to diffuse from a strip $(2 \times 8 \mathrm{~cm})$ of saturated Whatman filter paper no. 3 into the medium for $4 \mathrm{~h}$. Removal of the paper strip is followed by cross-streaking of the medium with the cultures to be studied. Incubation is carried out for $24 \mathrm{~h}$ at $37^{\circ} \mathrm{C}$ under $10 \% \mathrm{CO}_{2}$ and on the next day under aerobic conditions (Hajek, 1976). It is also possible to differentiate haemolysin activities according to the simpler method of Adamczyk \& Blaurock (1963). Agar plates are supplemented with washed sheep erythrocytes and the tested strains are inoculated perpendicularly to the streak of a standard $\beta$ haemolysin-producing Staphylococcus aureus strain. The results are evaluated as antagonistic $(\beta$ - $\alpha$-haemolysins) or synergistic ( $\beta$ - $\delta$-haemolysins) effects as determined by the shapes of haemolytic zones produced.

\section{Staphylolytic activity}

Except for Staphylococcus sciuri, Staphylococcus vitulinus and Staphylococcus lentus, staphylolytic activity is infrequently detected in the other staphylococcal species indigenous to lower mammals. This activity is at least in part due to the production of a staphylolytic enzyme that is immunologically related to lysostaphin but often encoded by a different gene. A quantitative analysis of staphylolytic enzyme production in culture supernatants may be performed using the method used by Kloos et al. (1997) in their description of Staphylococcus sciuri subspecies.

Most of the tests described above and some others, i.e. pyrrolidonyl arylamidase, arginine arylamidase, $\beta$ glucuronidase, $\beta$-galactosidase, can be performed using standardized miniaturized methods (Kloos \& Bannerman, 1994).

\section{Cytoplasmic membrane analysis}

(i) Teichoic acid type. Cell wall teichoic acids are watersoluble polymers containing repeating phosphodiester groups and are typical constituents of staphylococci. They consist of polyol (glycerol, ribitol), sugar and/or $\mathrm{N}$-acetylamino sugar. Most staphylococci contain glycerol or ribitol teichoic acids. These compounds consist of polymerized polyol phosphates that are substituted with various combinations of sugars and/or amino sugar residues, and also ester-linked D-alanine residues. Three classes of cell wall teichoic acids have been found in staphylococci, namely polyolphosphate, polyglycerolphosphate-glycosylphosphate and polyglycosylphosphate teichoic acids. Teichoic acids of the cell wall are covalently linked to the peptidoglycan through specific linkage units (Schleifer \& Kroppenstedt, 1990). Glycerol is detected enzymically by the method of Bergmeyer (1974). Phosphate levels are determined by the method of Ames (1966).
The screening method described by Endl et al. (1984) for determining the cell wall teichoic acid structure of staphylococci may be used. An overnight culture $(30 \mathrm{ml})$ is extracted with aqueous phenol to remove lipoteichoic acids. The extracted cells are lyophilized and treated with $0.5 \mathrm{ml} 70 \%(\mathrm{w} / \mathrm{w})$ hydrofluoric acid at $0{ }^{\circ} \mathrm{C}$ for $3-6 \mathrm{~h}$. The water-soluble degradation products of teichoic acids are neutralized, desalted and a portion is hydrolysed with $2 \mathrm{M} \mathrm{HCl}$ at $100^{\circ} \mathrm{C}$ for $3 \mathrm{~h}$. Both the unhydrolysed and the hydrolysed fractions are treated with trifluoroacetic anhydride, and the $N, O$-trifluoroacetyl derivatives are separated by GLC. The products identified in both chromatograms are sufficient to identify the type of teichoic acid (Endl et al., 1984; Schleifer et al., 1982).

(ii) Cellular fatty acids. The mean values of each of the fatty acids of 15-25 strains of one staphylococcal species are compared with those of other staphylococcal species and the Euclidian distance values are calculated. From these values, a dendrogram is constructed. The groups formed on the basis of the fatty acid compositions are in many cases in good agreement with the genomic relatedness derived from DNA homology studies (Gerhardt et al., 1994; Miller, 1982; Schleifer et al., 1976). As indicated in the review by Welch (1991), cellular fatty acid analysis combined with numerical analysis is recommended for describing a new staphylococcal species.

(iii) Polar lipids. Bacterial polar lipids are a heterogeneous group of molecules with amphipathic properties since the lipid is covently linked to a hydrophilic component. The most commonly occurring polar lipids are glycerophospholipids, in which fatty acids are esterified to positions $s n 1$ and 2 of the glycerol, and the polar function is linked to position 3 by a phosphodiester linkage. Polar lipids are analysed by one- or two-dimensional TLC (Minnikin et al., 1977, 1979).

(iv) Cytochrome patterns. Most staphylococci studied so far reveal only $a$-type and $b$-type cytochromes (Faller et al., 1980). However, several staphylococcal species exhibit some differences. For example, Staphylococcus lentus and Staphylococcus sciuri differ from all other staphylococci in lacking cytochrome $b_{552}$ and in containing two $c$-type cytochromes (Faller et al., 1980).

\section{Total protein profiles}

The whole-cell protein profile is determined by gel electrophoresis of cellular proteins. The detection methods include either Coomassie blue staining, $\left[{ }^{35}\right.$ S]methionine (radio-PAGE), or immunoblotting SDS-PAGE with Coomassie blue staining. RadioPAGE reveals all major bacterial proteins, while immunoblotting reveals surface-exposed antigens that are immunoreactive to antibodies. SDS-PAGE with Coomassie staining has produced distinct banding patterns for Staphylococcus species (Clink \& Pennington, 1987). Dryden et al. (1992) found that SDS-PAGE has a higher discriminatory power than 
immunoblotting. Because staphylococcal whole-cell polypeptide analysis has been evaluated as a good taxonomic and typing tool, it could be used as an additional test for describing a new Staphylococcus species.

\section{Protein A}

The determination of protein $\mathrm{A}$ is performed by the microgel diffusion method in $1.2 \%$ Special Agar Noble (Difco) in $0.05 \mathrm{M}$ Tris (hydroxymethyl)amino-methane buffer ( $\mathrm{pH} \mathrm{8.6)} \mathrm{against} 1 \%$ normal human gamma globulin. Cultures grown in brain-heart infusion at $37^{\circ} \mathrm{C}$ for $18 \mathrm{~h}$ are centrifuged and washed in $1 / 15 \mathrm{M}$ phosphate buffer ( $\mathrm{pH}$ 5.9). Sediments are resuspended in buffer in the ratio of $1: 5$, and then heated for $1 \mathrm{~h}$ in a water-bath at $100^{\circ} \mathrm{C}$. For a reference system, the crude protein A preparation is used (Hajek, 1976).

\section{Genotypic criteria}

The phylogenetic definition of a species generally would include strains with approximately $70 \%$ or greater DNA-DNA relatedness and with $5^{\circ} \mathrm{C}$ or less $\Delta T_{\mathrm{m}}$. It is preferable that both values should be considered. Phenotypic characteristics should agree with this definition (Wayne et al., 1987).

\section{DNA-DNA hybridization}

The Committee on reconciliation of approaches to bacterial systematics agreed on the need for a polyphasic study and an effective species description showing both phenotypic and genotypic distinction from other taxa (Murray et al., 1990). DNA-DNA hybridization studies rely on the renaturation property of DNA strands that are separated by heating. Closely related DNA strands are able to reanneal and form thermostable heteroduplexes, whereas distantly related DNAs yield low percentages of homology. DNA homology studies can be used to assess relationships only within narrow ranges of variation, as homology values fall to quite low levels (less than $30 \%$ ) for species that are only moderately different phenotypically (Grimont, 1988; Owen \& Pitcher, 1985).

Hybridization studies should include comparisons of the newly proposed type strain with other strains that are thought to belong to the proposed species, as well as with the type strains of all other staphylococcal species, to establish the level of intraspecific homogeneity and the levels of interspecific differences among the DNAs. No particular method to determine homology is recommended as different techniques, e.g. the S1 nuclease-trichloroacetic acid procedure, have proven to be reliable (Grimont et al., 1980; Huß et al., 1983), and can be applied to the study of staphylococcal DNAs without any special modification. But in case staphylococcal species are difficult to lyse (e.g. Staphylococcus sciuri), DNAs could be isolated and purified by using the procedures of Brenner et al. (1969), as modified by Kloos \& Wolfshohl (1979) and optimized for use with Staphylococcus sciuri by Kloos et al. (1997).

Percentage homologies must be interpreted with care, as the DNA renaturation rate depends on the experimental conditions, including sodium ion concentration, DNA concentration, DNA size and temperature. Discrepancies may occur between studies because different conditions are used (Grimont et al., 1980; Owen \& Pitcher, 1985). Analysis of the thermal stability of DNA hybrids $\left(T_{\mathrm{m}}\right)$ is a very useful measure of divergence between DNAs. Such an analysis involves stepwise thermal denaturation and can be carried out either by using hybrids formed on filters or free in solution. The spectrophotometric method should not be used because homologous and heterologous hybrids are mixed (Owen \& Pitcher, 1985). Analysis of thermal stability allows determination of the $\Delta T_{\mathrm{m}}$. The main advantage of $\Delta T_{\mathrm{m}}$ determination is that the value is not influenced by DNA size or by the method used (Grimont, 1988).

\section{Additional test Ribotyping}

Bacteria have been typed by comparison of fragments obtained from restriction endonuclease digests of total or chromosomal DNA (restriction fragment length polymorphisms, RFLP), but this has often produced complex patterns that have proved difficult to interpret (Ludwig et al., 1990). With hybridization RFLP technology, a subset of the fragments is selected, ideally with a universal probe. rRNA genes have sequences that are highly conserved in bacteria. Analysis of restriction fragments which include rRNA sequences (ribotyping) has emerged as a reliable means to extract features, the hybridized fragments, that group strains into a species structure. The hybridized fragments are anchored in the rRNA sequence, but some of the fragments extend to enzyme recognition sites in flanking regions. This permits characterizing information to be obtained from sequences likely evolving at different rates than most of the rRNA operons. The extent of grouping is modulated by the choice of enzyme. The expectation is that the choice of probe sequence and enzyme should group like genomes so that the derived group has a predictive capacity, for example the group is a species, subspecies or type. The characterizing pattern is an attribute of the strain, not a comparison of two strains, as is DNA-DNA hybridization. The pattern likely represents multiple strains of a type. Ribotyping has proved a useful technique for the identification of staphylococcal isolates (Chesneau et al., 1993; BialkowskaHobranska et al., 1990; De Buyser et al., 1989, 1992; Foster et al., 1997; Kloos et al., 1997; Izard et al., 1992; Meugnier et al., 1996; Thomson-Carter et al., 1989; Vandenesch et al., 1995; Webster et al., 1994) and such data in systematic descriptions reveal possible grouping errors, and show the positions of strains in the diversity represented by the same species name. Other genotypic methods show significant promise as 
tools for the identification of taxa belonging to a wider range of bacteria, for example PCR amplification of the 16S-23S spacer region (Busse et al., 1996; Dolzani et al., 1994; Gürtler \& Stanisich, 1996; Jensen et al., 1993; Leblond-Bourget \& Decaris, 1996) and DNA fingerprinting by infrequent-restriction site amplification (Mazurek \& Finn, 1996). They are not considered to be essential to a minimal standard description.

\section{REFERENCES}

Acar, J. F. \& Goldstein, F. W. (1986). Disk susceptibility test. In Antibiotics in Laboratory Medicine, pp. 27-63. Edited by V. Lorian. Baltimore: Williams \& Wilkins.

Adamczyk, B. \& Blaurock, G. (1963). Zum Nachweis spezifischer Staphylokokkenhämolysine. Z Ges Hyg 9, 456-471.

Ames, B. N. (1966). Assay of inorganic phosphate, total phosphate and phosphatase. Methods Enzymol 8, 115-118.

Bergmeyer, H. U. (1974). Methoden der Enzymatischen Analyse. Weinheim: Verlag Chemie.

Bialkowska-Hobrzanska, H., Harry, V., Jaskot, D. \& Hammerberg, O. (1990). Typing of coagulase-negative staphylococci by Southern hybridization of chromosomal DNA fingerprints using a rRNA probe. Eur J Clin Microbiol Infect Dis 9, 588-594.

Bouvet, P., Chatelain, R. \& Riou, J. Y. (1982). Intérêt du composé vibriostatique O/129 pour différencier les genres Staphylococcus et Micrococcus. Ann Inst Pasteur Microbiol 133B, 449-453.

Brenner, D. J., Fanning, G. R., Rake, A. \& Johnson, K. E. (1969). A batch procedure for thermal elution of DNA from hydroxyapatite. Anal Biochem 28, 447-459.

Busse, H. J., Denner, M. \& Lubitz, W. (1996). Classification and identification of bacteria: current approaches to an old problem. Overview of methods used in bacterial systematics. J Biotechnol 47, 3-38.

Cadness-Graves, B., Williams, R., Harper, G. J. \& Miles, A. A. (1943). Slide test for coagulase-positive staphylococci. Lancet $\mathbf{i}$, 736-738.

Chesneau, O., Morvan, A., Grimont, F., Labischinski, H. \& El Sohl, N. (1993). Staphylococcus pasteuri sp. nov., isolated from human, animal, and food specimens. Int J Syst Bacteriol 43, 237-244.

Christensen, W. B. (1946). Urea decomposition as a means of differentiating Proteus and paracolon cultures from each other and from Salmonella and Shigella types. J Bacteriol 52, 461-466.

Christie, R. \& Wilson, H. (1941). A test of staphylococcal fibrinolysis. Aust J Exp Biol Med Sci 19, 329-332.

Clink, J. \& Pennington, T. H. (1987). Staphylococcal whole-cell polypeptide analysis: evaluation as a taxonomic and typing tool. J Med Microbiol 23, 41-44.

Collins, M. D. (1981). Distribution of menaquinones within members of the genus Staphylococcus. FEMS Microbiol Lett 12, $83-85$.

Collins, M. D. \& Jones, D. (1981). Distribution of isoprenoid quinone structural types in bacteria and their taxonomic implications. Microbiol Rev 45, 316-354.

Collins, M. D., Pirouz, T., Goodfellow, M. \& Minnikin, D. E. (1977). Distribution of menaquinones in actinomycetes and corynebacteria. J Gen Microbiol 100, 221-230.

Cowan, S. T. \& Steel, K. J. (1965). Manual for the Identification of Medical Bacteria. New York: Cambridge University Press.
Davis, G. H. \& Hoyling, B. (1973). Use of a rapid acetoin test in the identification of staphylococci and micrococci. Int J Syst Bacteriol 23, 281-282.

De Buyser, M. L., Morvan, A., Grimont, F. \& El Solh, N. (1989). Characterization of Staphylococcus species by rRNA gene restriction patterns. J Gen Microbiol 135, 989-999.

De Buyser, M. L., Morvan, A., Aubert, S., Dilasser, F. \& El Sohl, N. (1992). Evaluation of rRNA gene probe for the identification of species and subspecies within the genus Staphylococcus. J Gen Microbiol 138, 889-899.

Devriese, L. A. \& Hajek, V. (1980). Identification of pathogenic staphylococci isolated from animals and foods derived from animals. J Appl Bacteriol 49, 1-11.

Dolzani, L., Tonin, E., Lagatolla, C. \& Monti-Bragadin, C. (1994). Typing of Staphylococcus aureus by amplification of the 16S-23S rRNA intergenic spacer sequences. FEMS Microbiol Lett 119, 167-174.

Dryden, M. S., Talsania, H. G., Martin, S., Cunningham, M., Richardson, J. F., Cookson, B., Marples, R. R. \& Phillips, I. (1992). Evaluation of methods for typing coagulase-negative staphylococci. J Med Microbiol 37, 109-117.

Endl, J., Seidl, P. H., Fiedler, F. \& Schleifer, K. H. (1984). Determination of cell wall teichoic acid structures of staphylococci by rapid chemical and serological screening methods. Arch Microbiol 137, 272-280.

Erdman, V. A., Wolters, J., Huysman, E. \& De Wachter, R. (1985). Collection of published 5S, 5.8S and 4.5S rRNA sequences. Nucleic Acids Res 13, 105-153.

Evans, J. B. \& Kloos, W. E. (1972). Use of shake cultures in a semisolid thioglycolate medium for differentiating staphylococci from micrococci. Appl Microbiol 23, 326-331.

Falk, J. \& Guering, S. G. (1983). Differentiation of Staphylococcus and Micrococcus spp. with the Taxo A bacitracin disk. J Clin Microbiol 18, 719-721.

Faller, A. H. \& Schleifer, K. H. (1981). Modified oxidase and benzidine tests for the separation of staphylococci from micrococci. J Clin Microbiol 13, 1031-1035.

Faller, A. H., Götz, F. \& Schleifer, K. H. (1980). Cytochrome patterns of staphylococci and micrococci and their taxonomic implications. Zentbl Bakteriol Parasitenkd Infektionskr Hyg Abt 1 Orig Reihe C 1, 26-39.

Fischer, S., Tsugita, A., Kreutz, B. \& Schleifer, K. H. (1983). Immunochemical and protein-chemical studies of class I fructose 1,6-diphosphate aldolases from staphylococci. Int $J$ Syst Bacteriol 33, 443-450.

Foster, G., Ross, H. M., Hutson, R. A. \& Collins, M. D. (1997). Staphylococcus lutrae sp. nov., a new coagulase-positive species isolated from otters. Int J Syst Bacteriol 47, 724-726.

Freney, J., Parlett, J. H., Goodfellow, M., Manchester, L., Meugnier, H. \& Fleurette, J. (1991). Fatty acid, polar lipid and isoprenoid quinone composition of Staphylococcus lugdunensis and Staphylococcus schleiferi. In The Staphylococci. Edited by J. Jeljaszewicz \& P. Ciborowski. Zentbl Bakteriol Suppl 21, 88-89.

Gerhardt, P., Murray, R. G. E., Wood, W. A. \& Krieg, N. R. (1994). Methods for General and Molecular Bacteriology. Washington, DC: American Society for Microbiology.

Götz, F., Nürnberger, E. \& Schleifer, K. H. (1979). Distribution, of Class I and Class II D-fructuose-1,6-bisphosphate aldolase in various Gram-positive bacteria. FEMS Microbiol Lett 5, 253-257.

Götz, F., Fischer, S. \& Schleifer, K. H. (1980). Purification and characterization of an unusually heat-stable and acid/base- 
stable class I fructose-1,6-bisphosphate aldolase from Staphylococcus aureus. Eur J Biochem 108, 295-301.

Grimont, P. A. D. (1988). Use of DNA reassociation in bacterial classification. Can J Microbiol 34, 541-546.

Grimont, P. A. D., Popoff, M. Y., Grimont, F., Coynault, C. \& Lemelin, M. (1980). Reproducibility and correlation study of three deoxyribonucleic acid hybridization procedures. Curr Microbiol 4, 325-330.

Gürtler, V. \& Stanisich, V. A. (1996). New approaches to typing and identification of bacteria using the $16 \mathrm{~S}-23 \mathrm{~S}$ rDNA spacer region. Microbiology 142, 3-16.

Hajek, V. (1976). Staphylococcus intermedius, a new species isolated from animals. Int J Syst Bacteriol 26, 401-408.

Hajek, V., Ludwig, W., Schleifer, K. H., Springer, N., Zitzelsberger, W., Kroppenstedt, R. M. \& Kocur, M. (1992). Staphylococcus muscae, a new species isolated from clinical specimens from cats. Int J Syst Bacteriol 39, 373-377.

Hajek, V., Meugnier, H., Bes, M., Brun, Y., Fiedler, F., Chmela, Z., Lasne, Y., Fleurette, J. \& Freney, J. (1996). Staphylococcus saprophyticus subsp. bovis subsp. nov., isolated from bovine nostrils. Int J Syst Bacteriol 46, 792-796.

Holt, J. G., Krieg, N. R., Sneath, P. H. A., Staley, J. T. \& Williams, S. T. (editors) (1994). Bergey's Manual of Determinative Bacteriology, 9th edn. Baltimore: Williams \& Wilkins.

Huß, V. A. R., Festl, H. \& Schleifer, K. H. (1983). Studies on the spectrophotometric determination of DNA hybridization from renaturation rates. Syst Appl Microbiol 4, 184-192.

Izard, N. C., Hächler, H., Grehn, M. \& Kayser, F. H. (1992). Ribotyping of coagulase-negative staphylococci with special emphasis on intraspecific typing of Staphylococcus epidermidis. $J$ Clin Microbiol 30, 817-823.

Jensen, M. A., Webster, J. A. \& Straus, N. (1993). Rapid identification of bacteria on the basis of polymerase chain reactionamplified rDNA spacer polymorphisms. Appl Environ Microbiol 59, 945-952.

Kloos, W. E. (1980). Natural populations of the genus Staphylococcus. Annu Rev Microbiol 34, 559-592.

Kloos, W. E. \& Bannerman, T. L. (1994). Update on clinical significance of coagulase-negative staphylococci. Clin Microbiol $\operatorname{Rev} 7,117-140$.

Kloos, W. E. \& Bannerman, T. L. (1995). Staphylococcus and Micrococcus. In Manual of Clinical Microbiology, 6th edn, pp. 282-298. Edited by P. R. Murray, E. J. Baron, M. A. Pfaller, F. C. Tenover \& R. H. Yolken. Washington, DC: American Society for Microbiology.

Kloos, W. E. \& Lambe, D. W. (1991). Staphylococcus. In Manual of Clinical Microbiology, 5th edn, pp. 222-237. Edited by A. Balows, W. J. Hausler, Jr, K. L. Herrmann, H. D. Isenberg \& H. J. Shadomy. Washington, DC: American Society for Microbiology.

Kloos, W. E. \& Schleifer, K. H. (1975a). Isolation and characterization of staphylococci from human skin. II. Descriptions of four new species: Staphylococcus warneri, Staphylococcus capitis, Staphylococcus hominis and Staphylococcus simulans. Int J Syst Bacteriol 25, 62-79.

Kloos, W. E. \& Schleifer, K. H. (1975b). Simplified scheme for routine identification of human Staphylococcus species. J Clin Microbiol 1, 82-88.

Kloos, W. E. \& Wolfshohl, J. F. (1979). Evidence for deoxyribonucleotide sequence divergence between staphylococci living on human and other primate skin. Curr Microbiol 3, $167-172$
Kloos, W. E., Tornabene, T. G. \& Schleifer, K. H. (1974). Isolation and characterization of micrococci from human skin, including two new species: Micrococcus lylae and Micrococcus kristinae. Int J Syst Bacteriol 24, 79-101.

Kloos, W. E., Schleifer, K. H. \& Götz, F. (1991). The genus Staphylococcus. In The Prokaryotes, 2nd edn, pp. 1369-1420. Edited by A. Balows, H. G. Trüper, M. Dworkin, W. Harder \& K. H. Schleifer. New York: Springer.

Kloos, W. E., Ballard, D. N., Webster, J. A. \& 12 other authors (1997). Ribotype delineation and description of Staphylococcus sciuri subspecies and their potential as reservoirs of methicillin resistance and staphylolytic enzyme genes. Int $J$ Syst Bacteriol 47, 313-323.

Kocur, M., Bergan, T. \& Mortensen, N. (1971). DNA base composition of Gram-positive cocci. J Gen Microbiol 69, 167-183.

Kovacs, N. (1956). Identification of Pseudomonas pyocyanea by the oxidase reaction. Nature 178, 703.

Lachica, R. V. F., Genigeorgis, C. \& Hoeprich, P. D. (1971). Metachromatic agar diffusion methods for detecting staphylococcal nuclease activity. Appl Microbiol 21, 585-587.

Lapage, S. P., Sneath, P. H. A., Lessel, E. F., Skerman, V. B. D., Seeliger, H. P. R. \& Clark, W. A. (editors) (1975). International Code of Nomenclature of Bacteria (1976 Revision). Bacteriological Code. Washington, DC: American Society for Microbiology.

Leblond-Bourget, N. \& Decaris, B. (1996). La séquence de l'espace intergénique $16 \mathrm{~S}-23 \mathrm{~S}$ : méthode rapide et fiable d'identification des souches bactériennes. Bull Soc Fr Microbiol 11, 7-10.

Loulergue, J., Pinon, G., Lauda, P. \& Audurier, A. (1984). La résistance à la fosfomycine chez Staphylococcus saprophyticus et chez les autres espèces de staphylococques à coagulase négative. Ann Microbiol (Paris) 135A, 239-247.

Ludwig, W., Weizenegger, M., Dorn, S., Andreesen, J. \& Schleifer, K. H. (1990). The phylogenetic position of Peptococcus niger based on 16S rRNA sequence studies. FEMS Microbiol Lett 71, 139-144.

Marica, D., Vasiu, C. \& Klemm, W. (1974). Untersuchungen zu den inner- und zwischenartlichen Beziehungen bei Bakterienhämolysinen. I. Mitteilung. Das Konzept der Maskierung hämolytischer Fraktionen bei Staphylococcus pyogenes; die "Serum-De-maskierung" ein neuer Test zur Identifizierung der Alpha-Fraktion (Alpha-Lysin) im Exotoxinkomplex von Staphylokokken tierischer Herkunft. Zentbl Vet Reihe B21, 455-466.

Mazurek, J. \& Finn, F. (1996). DNA fingerprinting by infrequentrestriction site amplification. $J$ Clin Microbiol 34, 2386-2390.

Meugnier, H., Bes, M., Vernozy-Rozand, C., Mazuy, C., Brun, Y., Freney, J. \& Fleurette, J. (1996). Identification and ribotyping of Staphylococcus xylosus and Staphylococcus equorum strains isolated from goat milk and cheese. Int $J$ Food Microbiol 31 , 325-331.

Miller, L. T. (1982). Single derivatization method for routine analysis of bacterial whole cell fatty acid methyl esters, including hydroxy acids. $J$ Clin Microbiol 16, 584-586.

Miller, L. T. \& Berger, T. (1985). Bacteria Identification by Gas Chromatography of Whole Cell Fatty Acids. Hewlett Packard Application Note 228-241.

Minnikin, D. E., Patel, P. V., Alshamaony, L. \& Goodfellow, M. (1977). Polar lipid composition in the classification of Nocardia and related bacteria. Int $J$ Syst Bacteriol 27, 104-117.

Minnikin, D. E., Collins, M. D. \& Goodfellow, M. (1979). Fatty 
acid and polar lipid composition in the classification of Cellulomonas and related taxa. Int J Syst Bacteriol 47, 87-95.

Moeller, V. (1955). Simplified tests for some amino acid decarboxylases and for the arginine dihydrolase system. Acta Pathol Microbiol Scand 36, 158-172.

Murray, R. G. E., Brenner, D. J., Colwell, R. R., De Vos, P., Goodfellow, M., Grimont, P. A. D., Pfennig, N., Stackebrandt, E. \& Zavarzin, G. A. (1990). International Committee on Systematic Bacteriology. Report of the ad hoc committee on approaches to taxonomy within the Proteobacteria. Int J Syst Bacteriol 40, 213-215.

Naylor, H. B. \& Burgi, E. (1956). Observations on abortive infection of Micrococcus lysodeikticus with bacteriophage. Virology 2, 577-593.

Owen, R. J. \& Pitcher, D. (1985). Current methods for estimating DNA base composition and levels of DNA-DNA hybridization. In Microbiology, pp. 67-93. Edited by M. Goodfellow \& D. E. Minnikin. London: Academic Press.

Pennock, C. A. \& Huddy, R. B. (1967). Phosphatase reaction of coagulase-negative staphylococci and micrococci. $J$ Pathol Bacteriol 93, 685-688.

Saitou, N. \& Nei, M. (1987). The neighbour-joining method: a new method for reconstructing phylogenetic trees. Mol Biol Evol 4, 406-425.

Schleifer, K. H. (1986). Family I Micrococcaceae Prevot, $31^{\mathrm{AL}}$. In Bergey's Manual of Systematic Bacteriology, vol. 2, pp. 1003-1035. Edited by P. H. A. Sneath, N. S. Mair, M. E. Sharpe \& J. G. Holt. Baltimore: Williams \& Wilkins.

Schleifer, K. H. \& Kandler, O. (1972). Peptidoglycan types of bacterial cell walls and their taxonomic implications. Bacteriol $\operatorname{Rev} 36,407-477$

Schleifer, K. H. \& Kloos, W. E. (1975a). Isolation and characterization of staphylococci from human skin. I. Amended descriptions of Staphylococcus epidermidis and Staphylococcus saprophyticus, and descriptions of three new species: Staphylococcus cohnii, Staphylococcus haemolyticus, and Staphylococcus xylosus. Int J Syst Bacteriol 25, 50-61.

Schleifer, K. H. \& Kloos, W. E. (1975b). A simple test system for the separation of staphylococci from micrococci. $J$ Clin Microbiol 1, 337-338.

Schleifer, K. H. \& Kroppenstedt, R. M. (1990). Chemical and molecular classification of staphylococci. J Appl Bacteriol (symp. suppl.) 69, 9S-24S.

Schleifer, K. H., Hammes, W. P. \& Kandler, O. (1976). Effect of endogenous and exogenous factors on the primary structures of bacterial peptidoglycan. Adv Microb Physiol 13, 245-292.

Schleifer, K. H., Kilpper-Bälz, R., Fischer, U., Faller, A. \& Endl, J.
(1982). Identification of 'Micrococcus candidus' ATCC 14852 as a strain of Staphylococcus epidermidis and of 'Micrococcus caseolyticus' ATCC 13548 and 'Micrococcus varians' ATCC 29750 as members of a new species: Staphylococcus caseolyticus. Int J Syst Bacteriol 32, 15-20.

Schleifer, K. H., Leuteritz, M., Weiss, N., Ludwig, W., Kirchhof, G. \& Seidel-Rüffer, H. (1990). Taxonomic study of anaerobic, Gramnegative, rod-shaped bacteria from breweries: amended description of Pectinatus cerevisiiphilus and description of Pectinatus frisingensis sp. nov., Selenomonas lacticifex sp. nov., Zymophilus raffinosivorans gen. nov., sp. nov., and Zymophilus paucivorans sp. nov. Int $J$ Syst Bacteriol 40, 19-27.

Sierra, G. (1957). A simple method for the detection of lipolytic activity of micro-organisms and some observations on the influence of the contact between cells and fatty substrates. Antonie Leeuwenhoek J Microbiol Serol 23, 15-22.

Subcommittee on the taxonomy of staphylococci and micrococci (1965). Recommendations. Int Bull Bacteriol Nomencl Taxon 15, 109-110.

Takebe, I. (1965). Extent of cross-linkage in the murein sacculus of Escherichia coli B cell wall. Biochim Biophys Acta 101, 124-126.

Tamaoka, J., Katayama-Fujimura, Y. \& Kuraishi, H. (1983). Analysis of bacterial menaquinone mixtures by high performance liquid chromatography. $J$ Appl Bacteriol 54, 31-36.

Thomson-Carter, F. M., Carter, P. E. \& Pennington, T. H. (1989). Differentiation of staphylococcal species and strains by rRNA gene restriction patterns. J Gen Microbiol 135, 2093-2097.

Vandenesch, F., Eykyn, S., Bes, M., Meugnier, H., Fleurette, J. \& Etienne, J. (1995). Identification and ribotypes of Staphylococcus caprae isolates as human pathogens and from goat milk. J Clin Microbiol 33, 888-892.

Wayne, L. G., Brenner, D. J., Colwell, R. R. \& 9 other authors (1987). International Committee on Systematic Bacteriology. Report of the ad hoc committee on reconciliation of approaches to bacterial systematics. Int J Syst Bacteriol 37, 463-464.

Webster, J. A., Bannerman, T. L., Hubner, R. J., Ballard, D. N., Cole, E. M., Bruce, J. L., Fiedler, F., Schubert, K. \& Kloos, W. E. (1994). Identification of the Staphylococcus sciuri species group with EcoRI fragments containing rRNA sequences and description of Staphylococcus vitulus sp. nov. Int $J$ Syst Bacteriol 44, 454-460.

Welch, D. F. (1991). Applications of cellular fatty acid analysis. Clin Microbiol Rev 4, 422-438.

Willis, A. T., O'Connor, J. \& Smith, J.A. (1966). Colonial pigmentation of Staphylococcus aureus. J Pathol Bacteriol 92 , 97-105. 